Research Article

\title{
Study on the Effect of Mineral Particle Sizes on the Spectral Characteristics of Sound and Vibrations in Rock Drilling
}

\author{
Zhantao Li, ${ }^{1,2}$ Sui Wang, ${ }^{1,2}$ Jicheng Wang, ${ }^{1,2}$ Chunxia Song, ${ }^{1,2}$ and Bin Chen $\mathbb{D}^{1,2}$ \\ ${ }^{1}$ School of Civil and Transportation Engineering, Ningbo University of Technology, Ningbo, Zhejiang 315211, China \\ ${ }^{2}$ Soft Soil Research Center, Ningbo University of Technology, \\ State Key Laboratory of Geomechanics and Geotechnical Engineering, Ningbo, Zhejiang 315211, China
}

Correspondence should be addressed to Bin Chen; chenbinnjwhnb@tom.com

Received 20 September 2019; Revised 14 February 2020; Accepted 14 May 2020; Published 30 June 2020

Academic Editor: Franck Poisson

Copyright (C) 2020 Zhantao Li et al. This is an open access article distributed under the Creative Commons Attribution License, which permits unrestricted use, distribution, and reproduction in any medium, provided the original work is properly cited.

\begin{abstract}
This study aimed to investigate the relationships between particle sizes and spectral characteristics of the sound or vibration signals generated in rock drilling processes. Several drilling experiments were conducted on concrete specimens of different aggregate sizes. By using an indoor signal acquisition and analysis system, data from the sound waves and vibrations were collected, the characteristic signals were extracted, and the spectral characteristics of the sound and vibrations of different aggregate sizes were identified. An approach based on frequency band analysis was adopted. In this approach, the average amplitude of each frequency band was calculated after frequency segmentation. The overall distribution trend in the frequency domain is conveniently observed, and the trend line patterns reflect the effect of aggregate sizes. The time-domain features of sound and vibration, such as the amplitude of sound pressure and vibration, are important indexes that roughly reflect grain sizes. The general trend is that the larger the amplitudes of sound and vibration, the larger the grain size. The frequency domain features of sound and vibration, such as the distribution of energy at high and low frequencies, can also reflect grain sizes. The general trend is that the larger the high-frequency composition of sound and vibration, the smaller the aggregate size. These results are useful for revealing the influence mechanism of rock particle sizes on the vibration spectral characteristics in drilling processes. The study provides a possibility for developing a method to evaluate the information on rock structures collected from drilling vibration or sound signals for the fine exploration of geological surveys.
\end{abstract}

\section{Introduction}

In the field of geological and engineering drilling, traditional methods are primarily based on the properties of rock cores, the composition of rock powders, and the changes in the color of drilling fluids to judge the lithology, rock joints, properties, depth, and sizes of geological anomaly bodies. However, the performances of these methods are not satisfactory for the formations of weathered rocks, grit, and soft rock. Moreover, rock samples removed through drilling often cannot reflect the integrity of the original rocks [1]. Recently, there have been some advances in the field of measurement while drilling (MWD) technology based on drilling mechanical parameters (drilling speed, thrust, energy, speed, etc.) [2-10]. The drilling mechanical parameters have good continuity and strong capacity for identifying the formations of loose rocks, but they are not sufficiently sensitive to the rock's lithology, and the identification accuracy still needs to be improved [1].

The drilling process is a complex rock fragmentation process involving impacting, rolling, grinding, cutting, etc. by the drill bit on rocks. In this process, the physical-mechanical properties of the rock (cementation, particle, porosity, strength, hardness, and anisotropy) and the physical-mechanical properties of the rock mass (rock integrity, effect of water) will affect the characteristic drill stem vibration and sound signals [1]. Therefore, there must be abundant information on rock formation in the sound and vibration signals. These vibroacoustic signals have excellent continuity and sensitivity and are not disturbed by any 
electromagnetic signals. Significant progress has been made in studies concerning the vibration and sound characteristics during rock drilling.

Some researchers qualitatively investigated the relationships between the amplitudes of vibroacoustic signals and the rock types. Al-Shuker et al. inferred formation changes from drill stem vibration signals by using the artificial neural network (ANN) method [11]. Esmaeili et al. investigated the effect of rock compression strength on the vibration characteristics of the drill stem during oil well drilling. They used concrete, limestone, sandstone, dolomite, and other stones with different strengths and hardness values as experimental materials and observed that there are significant differences in the vibration amplitudes of drilling [12]. Guo developed a detector for the formation of roof rocks in coal beds based on vibration-while-drilling characteristics and ancillary data processing systems, collected drill pipe vibration signals, and indicated that the drilling time and the standard deviation, interval, and probability of amplitude can be used as the main indicators for determining the nature of rock formations [13]. Li proposed an estimation model for rock strength based on the P-wave modulus (the product of rock density and P-wave velocity squared) and verified this model by using two types of lithological rock data. The results show that there is a good linear correlation between $\mathrm{P}$-wave modulus and rock strength. Moreover, the correlation among impact rate, stress wave energy loss rate, and rock strength index during percussion drilling was investigated. It was observed that, as the impact energy increases, the effect of voids on the stress wave response increases [14]. Chen et al. studied rock vibration under impact drilling. It was observed that the rock characteristics are closely related to vibrations. The rock density, stiffness, and compressive strength can influence rock vibration; among these factors, the rock strength has the most evident effect on the vibration. The smaller the rock stiffness, the lower the strength, and the greater the rock vibration [15].

Furthermore, many researchers qualitatively extracted lithology information via the spectral analyses of vibration signals. For example, Jin et al. used cement-cured soil and gravel as experimental materials. Based on the short-time Fourier transform analysis, the vibration signal of drill string in the range of $6000-8000 \mathrm{~Hz}$ was studied. It was observed that a high-frequency pulse energy could distinguish between two materials [16]. Shreedharan et al. studied soundcharacteristic-based lithology identification and concluded that the dominant frequencies of the drilling sound signals can be used as acoustic fingerprinting to distinguish different rocks [17]. While studying the spectral properties of drill stem vibrations, Gao indicated that the vibration of a drill stem at $7-10 \mathrm{kHz}$ can be used to distinguish typical rocks, discovered the spectral characteristics of several types of typical rocks (sandstone, shale, concrete, grit rock, siltstone, mudstone, and crystal grain limestone), and stated qualitatively that the primary differences lie in the location, height, and number of spectral peaks [18-20]. Liu et al. also discovered that the rock types can be determined using the frequency characteristics of the vibration waves of a drill stem. They used a maximum entropy model and improved the accuracy of logging [21]. Li et al. applied vibration and sound MWD techniques to the identification of weathering crust, and they obtained desirable results [22]. Lesso et al. observed the effect of lithology on vibration characteristics when evaluating drill-stem-vibration-based drilling quality. They developed a new approach by implementing the vibration signal as a vector in a Hilbert space to classify rocks [23]. Han processed MWD vibration data by using variance analysis and energy analysis of the vibration signals of a drill stem and successfully identified the hardness changes in rock formations, thus confirming the effectiveness of the MWD vibration of mine drilling rigs [24].

The above studies focused on lithology identification and qualitatively verified that sound and vibration signals have a strong correlation with lithology. Recently, some studies have presented semiquantitative results. For example, Vardhan et al. determined that increased compressive strength and lower abrasivity of rocks will require higher air pressure and thrusts to achieve an optimum penetration rate, thus resulting in higher sound level at the operator's position [25]. Li established a dynamic drill string model and implemented indoor drilling experiments with iron plates, aluminum plates, and wooden boards. It was observed that the frequency band ranges are significantly different; the iron plate had the smallest frequency range whereas the wooden board had the largest. Field experiments have also confirmed that the frequency spectrum can reflect lithological changes [26]. Liu et al. studied the relationship between the drill stem vibration and lithology by using the digital simulation method and determined that transverse vibration radius, vertical vibration amplitude, and tangential vibration amplitude correlate with the rock hardness [27]. In our preliminary research, an indoor drilling vibration signal acquisition system was developed. Drilling experiments were performed on typical geotechnical materials such as limestone, marble, granite, and aerated concrete. The data of drilling sound waves and rock vibration signals were collected. The frequency analysis was used. The spectral characteristics of drill stem vibration and sound were revealed. The results showed the feasibility and optimistic prospect of the quantitative analysis and identification of rock drilling spectrum properties [28].

The above studies showed that the sound and drill stem vibration signals in the drilling process can reflect rock formation and are beneficial for sound-vibration-based lithology identification. However, quantitative research in this field is inadequate so far. To estimate the physical mechanical properties of a rock mass quantitatively, two important problems need to be tackled. First, a database regarding the relations between the rock properties stated above and the characteristics of sound and vibration must be created. Second, how to exclude multiplicity is also a difficult subject. Several researchers have attempted to tackle these two problems. For example, Kumar et al. proposed a group of multiple regression formulas predicting the uniaxial compressive strength (UCS), tensile strength (TS), or porosity from the drill bit diameter, drill bit speed, penetration rate, and equivalent sound level produced during drilling 
[29]. Subsequently, they used two methods-an ANN method and a regression method-for the prediction of rock properties such as UCS, Schmidt rebound number (SRN), dry density, P-wave velocity, tensile strength, Young's modulus, and percentage porosity from the variation of the equivalent sound level produced during drilling [30, 31]. Recently, this team processed the noise signals in rock drilling by using the fast Fourier transform (FFT) method to obtain five dominant frequencies and observed that there is a significant correlation between the dominant frequencies and the physical properties such as tensile strength, compressive strength, and density [32, 33]. Furthermore, a multiple regression method was employed to derive the above rock properties from the dominant frequencies and the drill diameter, feed rate, and drilling speed [34]. Masood developed special equipment and conducted igneous rock drilling experiments. It was observed that the drilling sound intensity will increase nonlinearly with the increase in the rock physical properties such as UCS, TS, SRN, density, and abrasivity [35]. In Liu et al.'s study, through the laboratory experiments of rock drills with roller cones, the sound vibration data of the drill bit when drilling into sandstone, shale, cement ring, and casing at different weights were collected. From the time-frequency processed digital signals, 50 eigenvalues in the time and frequency domain were extracted, the "fingerprint" features of the drill bit signals for different drilling conditions were selected, and finally, a new method for lithology identification from this "fingerprint" information was established [36].

In addition to the above studies on the sound and vibration signals in rock drilling, studies on other rock processing methods exist. Li used the wavelet transform method to study the relationship between the vibration spectrum characteristics and lithology when the shearer cuts the rocks. It was observed that the harder the rock, the more energy in the high-frequency signals is concentrated on the highresolution scale. Moreover, through the energy spectrum analysis, it was observed that the rock hardness coefficient increases with increasing vibration frequency and decreasing vibration amplitude [37]. Delibelata et al. observed that the noise level in the action of rock sawing has a strong correlation with the physical properties of the rock. Specifically, the higher the rock strengths including UCS, Brazilian tensile strength, and point load strength, the higher the noise level. The noise level is a power function of the rock strength. The higher the density, the higher the noise level. There is a linear relationship between these two parameters. The higher the porosity, the lower the noise level. There is also a linear relationship between the two parameters [38]. These results in rock cutting can also be used for reference in rock drilling.

However, few studies investigated the relationship between the structural parameters of rocks and the vibroacoustic characteristics in rock drilling processes, which is a more fundamental problem. Mineralogical composition, microcracks, porosity, grain size, grain shape, and the degree of foliation were observed to be the most important petrographic parameters influencing the mechanical and technical properties of igneous, metamorphic, and sedimentary rocks [39]. Particularly, the grain size effect on the physical-mechanical properties of rocks has been widely studied [40]. The typical grain size has been observed to be the main microstructural factor controlling the strength variation in groups of rocks that are closely related mineralogically [39, 41-43]. Hence, instead of the mechanical properties of the rock, the effect of grain sizes on the vibroacoustic characteristics in rock drilling was studied herein. Aggregates of different sizes were used to prepare concrete specimens and perform drilling experiments to determine the relationships between the rock structural characteristics and the drilling spectrum properties.

\section{Experiments on the Acquisition and Analysis of Sound and Vibration Signals in Rock Drilling}

2.1. Specimen Preparation. This study aims to reveal the relationship between the grain sizes and vibroacoustic characteristics in rock drilling. However, rock is a natural material formed from one or more minerals and observed in the Earth's crust. It is a discontinuous, nonuniform, anisotropic substance with defects, structural damage, joints, and weak interfaces. These properties of rocks will lead to considerable variation in test results. Therefore, rock is not a proper experimental material for this study. Considering the convenience of controlling the experimental variables, concrete was chosen as the geotechnical material for use in the experiments.

The drilling experiments were conducted by using concretes of different aggregate sizes to simulate the effect of rock grain sizes on the vibration properties. Ordinary Portland cement $425 \#$ was used. The same batch of stones was sieved to five grades through a set of crushed stone sieves: $<0.5 \mathrm{~mm}, 0.5-1.7 \mathrm{~mm}, 1.7-7.1 \mathrm{~mm}, 7.1-22 \mathrm{~mm}$, and 22-32 $\mathrm{mm}$. Correspondingly, the average sizes of these five groups are $0.25 \mathrm{~mm}, 1.1 \mathrm{~mm}, 4.4 \mathrm{~mm}, 14.55 \mathrm{~mm}$, and $27 \mathrm{~mm}$, respectively. No admixtures or additives were added. To eliminate the effect of specimen sizes and forms, all the specimens were made into cylinders of diameter $110 \mathrm{~mm}$ and length $200 \mathrm{~mm}$. The precision conforms to the national standard (GB/T 50081-2002). The aggregate sizes of the specimens showed no correlation with the total weight; hence, the effect of specimen weight on the vibration spectrum could be excluded. The properties of the concrete specimens are shown in Table 1, and the appearance of the concrete specimens is shown in Figure 1.

2.2. Experimental Equipment. Compared with field experiments in which only drill stem vibration signals can be measured, one of the advantages of indoor experiments is that they can directly detect the vibration signals of concrete specimens and provide a comprehensive view of the lithology; consequently, they can extract useful information about the properties of specimens.

Figure 2 shows an indoor drilling equipment and data acquisition system. This system can acquire sound waves and vibration signals while drilling. The experimental equipment and specifications are shown in Table 2. In contrast to 
TABle 1: Properties of rock samples.

\begin{tabular}{lcccccc}
\hline Sample no. & Aggregate size range $(\mathrm{mm})$ & Average aggregate size $(\mathrm{mm})$ & Mass $(\mathrm{g})$ & UCS $(\mathrm{MPa})$ & TS $(\mathrm{MPa})$ & P-wave velocity $(\mathrm{m} / \mathrm{s})$ \\
\hline 1 & $<0.5$ & 0.25 & 3014.7 & 23 & 1.8 & 3871 \\
2 & $0.5-1.7$ & 1.1 & 3027.8 & 20 & 2.1 & 3700 \\
3 & $1.7-7.1$ & 4.4 & 2697.9 & 21 & 2.0 & 3999 \\
4 & $7.1-22$ & 14.55 & 2746.4 & 25 & 2.2 & 3780 \\
5 & $22-32$ & 27 & 2450.8 & 22 & 1.9 & 4211 \\
\hline
\end{tabular}

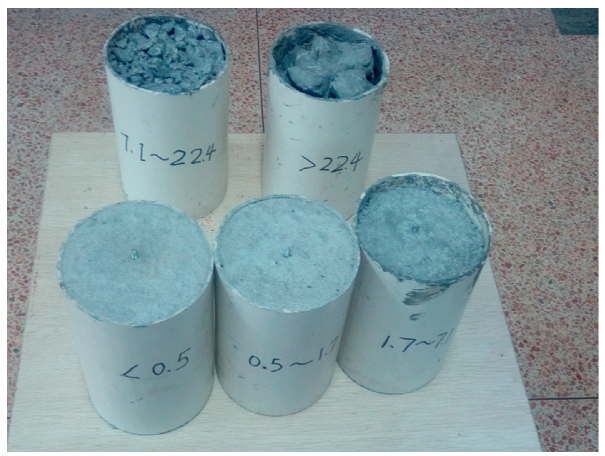

FIGURE 1: Appearance of concrete specimens used for rock drilling experiments.
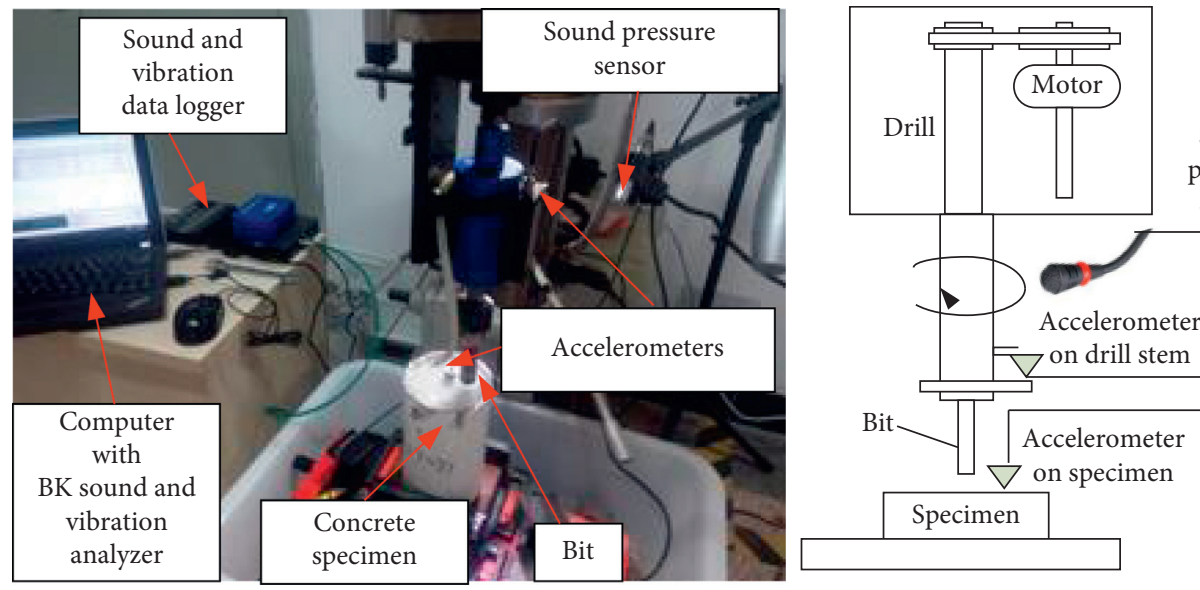

Computer with sound and vibration analyzer pressure sensor
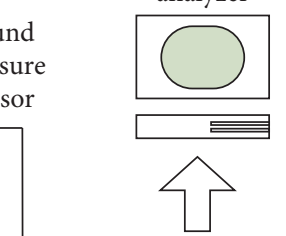

FIGURE 2: Drilling and sound/vibration signal acquisition system.

TABLE 2: Specifications of the experimental equipment.

\begin{tabular}{|c|c|c|c|}
\hline Name & Model & Specification/function & Manufacturer \\
\hline Drill & ZB4132GP & Maximum borehole diameter $31.75 \mathrm{~mm}$ (for steel) & Zhejiang Xiling Co., Ltd. \\
\hline $\begin{array}{l}\text { Sound and vibration } \\
\text { data logger }\end{array}$ & BK 3053-B-120 & $\begin{array}{l}\text { 4-channel/24-bit AD/4-AD full parallel/51.2 kHz per } \\
\text { channel }\end{array}$ & $\begin{array}{l}\text { Brüel \& Kjær Sound \& } \\
\text { Vibration Measurement A/S } \\
\text { (HQ) }\end{array}$ \\
\hline $\begin{array}{l}\text { BK sound and } \\
\text { vibration analyzer }\end{array}$ & $\begin{array}{l}\text { PULSE LabShop } \\
\text { Version v20.0.0.455 }\end{array}$ & $\begin{array}{c}\text { Signal processing functions such as oscilloscope } \\
\text { sampling, time-domain analysis, auto spectral analysis, } \\
\text { and format converter }\end{array}$ & $\begin{array}{c}\text { Brüel \& Kjær Sound \& } \\
\text { Vibration Measurement A/S } \\
\text { (HQ) }\end{array}$ \\
\hline Accelerometer & YD-9 & $\begin{array}{c}\text { Range } 2000 \mathrm{~ms}^{-2} \text {, frequency } 1-30000 \mathrm{~Hz}(+5 \%) \text {, } \\
\text { sensitivity } 5.13 \mathrm{pc} / \mathrm{ms}^{-2}\end{array}$ & $\begin{array}{l}\text { Shanghai Zhurui Automation } \\
\text { Technology Co., Ltd. }\end{array}$ \\
\hline $\begin{array}{l}\text { Sound pressure } \\
\text { sensor }\end{array}$ & INV9206 & $20-20 \mathrm{kHz} / 20-146 \mathrm{~dB} / \mathrm{ICP}$ & $\begin{array}{l}\text { China Orient Institute of Noise } \\
\text { \& Vibration }\end{array}$ \\
\hline
\end{tabular}

previous experiments, the experiments in this study use ZB4132GP, which is a numerical controlled (NC) vertical driller that can feed automatically compared to portable drills; moreover, its drilling feed rate can be precisely controlled. Therefore, the effect of the penetration rate on the vibration and sound characteristics can be excluded. The 
important specifications of the NC driller used were as follows:

(i) Maximum borehole diameter (for steel): $31.75 \mathrm{~mm}$

(ii) Maximum travel of spindle: $150 \mathrm{~mm}$

(iii) Power supply: $380 \mathrm{~V}$, three-phase, $50 \mathrm{~Hz}, 1.5 \mathrm{~kW}$

(iv) Rotary speed: 5 speeds, $280-1875 \mathrm{r} / \mathrm{min}$

(v) Feed rate: $0-113.4 \mathrm{~mm} / \mathrm{min}$

The data acquisition system consists of a computer, sound pressure transducer (INV9206), two accelerometers (YD-9), and data acquisition card hardware along with analysis software (BK 3053-B-120 from Brüel and Kjær). The sound pressure transducer is used to acquire the drilling sound signals. One accelerometer is fixed at the top surface of the concrete specimen to acquire the vertical vibration signals of the specimen. Another accelerometer is glued to the drill stem to acquire its vibration signals. These sensors are connected to the BK 3053-B-120 data acquisition hardware with data cables, which are connected to a personal computer with a Windows operating system (64 bit).

2.3. Methodology. The experiments were performed inside a closed laboratory without external noise perceivable by human ear. In this case, the results are more accurate. During these experiments, impregnated diamond core bits with an inner diameter of $20 \mathrm{~mm}$ were used. The bits were always maintained sharp and were replaced by new ones in a timely manner before they became blunt. A vise was fastened firmly to the drill machine. A small water pump was used for circulating the cooling water. The flow remained steady while drilling.

The drilling experiment was conducted for each concrete specimen. Through each experiment, the specimen maintained a clamped state with a bench vise. The rotary speed was set at $280 \mathrm{rpm}$, because the drilling process can reach its most stable state, and the integrity of the cores is best under these drilling conditions for the machine. At least four clips of sound waves and vibration signals were acquired by using the BK PULSE Smart Signal Acquisition System. The feed rates of these clips were $33.1 \mathrm{~mm} / \mathrm{min}, 47.4 \mathrm{~mm} / \mathrm{min}$, $71.6 \mathrm{~mm} / \mathrm{min}$, and $87.7 \mathrm{~mm} / \mathrm{min}$. Correspondingly, the required time for a complete rotation of the drill bit under any feed rate is $0.214 \mathrm{~s}$. The sampling frequency was $32768 \mathrm{~Hz}$. Each clip lasted more than $10 \mathrm{~s}$. The drilling machine was set at an automatic feed mode. Because these experiments were performed indoors, the noise in the surrounding environment was weak, and the drilling conditions remained unchanged. Therefore, no additional preprocessing is required after excluding abnormal data.

According to the above experimental design, there were four grades of feed rates, three types of signals, and five types of concrete specimens; accordingly, the number of total test conditions was $4 \times 3 \times 5=60$. The repeatability and reliability of this study are accepted.

The amplitudes of the vibration signals acquired are the acceleration values, which, after two-stage time-integrations, are taken as vibration amplitudes. For the sake of convenience, this study uses acceleration values as indexes.
There are several spectral analysis technologies and methods, and their number continues to increase. The wavelet transform and Fourier transform are the most commonly used methods. The goal of this study is lithology identification, and lithology indicates the statistical properties of rocks above a certain volume scale; therefore, the wavelet transform is not applicable. The Fourier transform method, which can transform a time-domain signal to the frequency domain and is suitable for stable signal analysis, was adopted in this study. Because the basic Fourier transform is a continuous function, we used the discrete Fourier transform (DFT) to process the signals. The transformation result of DFT is an equally spaced sampling of the time-domain discrete signal spectrum, so that the frequency-domain function is also discrete. Consequently, digital signal processing technology can also perform frequency domain analysis on a computer platform and thus become more flexible. Let the length of the sequence $x(n)$ be $M$. The definition of $N$-point DFT of $x(n)$ is

$$
\operatorname{DFT}[x(n)]_{N}=\sum_{n=0}^{N-1} x(n) e^{-j 2 \pi / N k n}, \quad k=0,1, \ldots, N-1 .
$$

Because of the high time complexity of DFT, FFT was proposed to improve the computational efficiency. FFT continuously decomposes long sequences into short sequences and uses a fast algorithm of periodicity and symmetry and some special values to reduce the amount of operations [44]. Moreover, FFT has a lower threshold of signal-to-noise ratio. This study uses FFT to observe the spectral characteristics of the sound waves while drilling specimens.

\section{Time-Domain Analysis of the Effect of Concrete Aggregate Sizes on the Drilling Sound and Vibrations}

A time-domain analysis of the drilling sound signals was conducted, and Figure 3 shows a part of the captured results. The waveform is irregular, and signal characteristics cannot be extracted. The aggregate sizes of the specimens cannot be differentiated clearly in accordance with the waveform characteristics. Several measures of statistical dispersion including variance, standard deviation, kurtosis, and skewness were employed, but they did not yield valuable information.

The sound pressure of the drilling sound, the average acceleration values of the specimen vibration, and the drill stem vibration at each feed rate are shown in Table 3. Figures 4-6 show the scatter plots of the average aggregate size and amplitude. The abscissa of each plot represents the average aggregate size, and the vertical ordinate represents the average amplitude of the sound pressure of the drilling sound (Figure 4), specimen vibration (Figure 5), and drill stem vibration (Figure 6). It can be observed that, at different feed rates, the sound pressure of the drilling sound, specimen vibration, and drill stem vibration amplitude show a correlation with the aggregate size of the specimen. The general trend is that the larger the aggregate size, the greater 

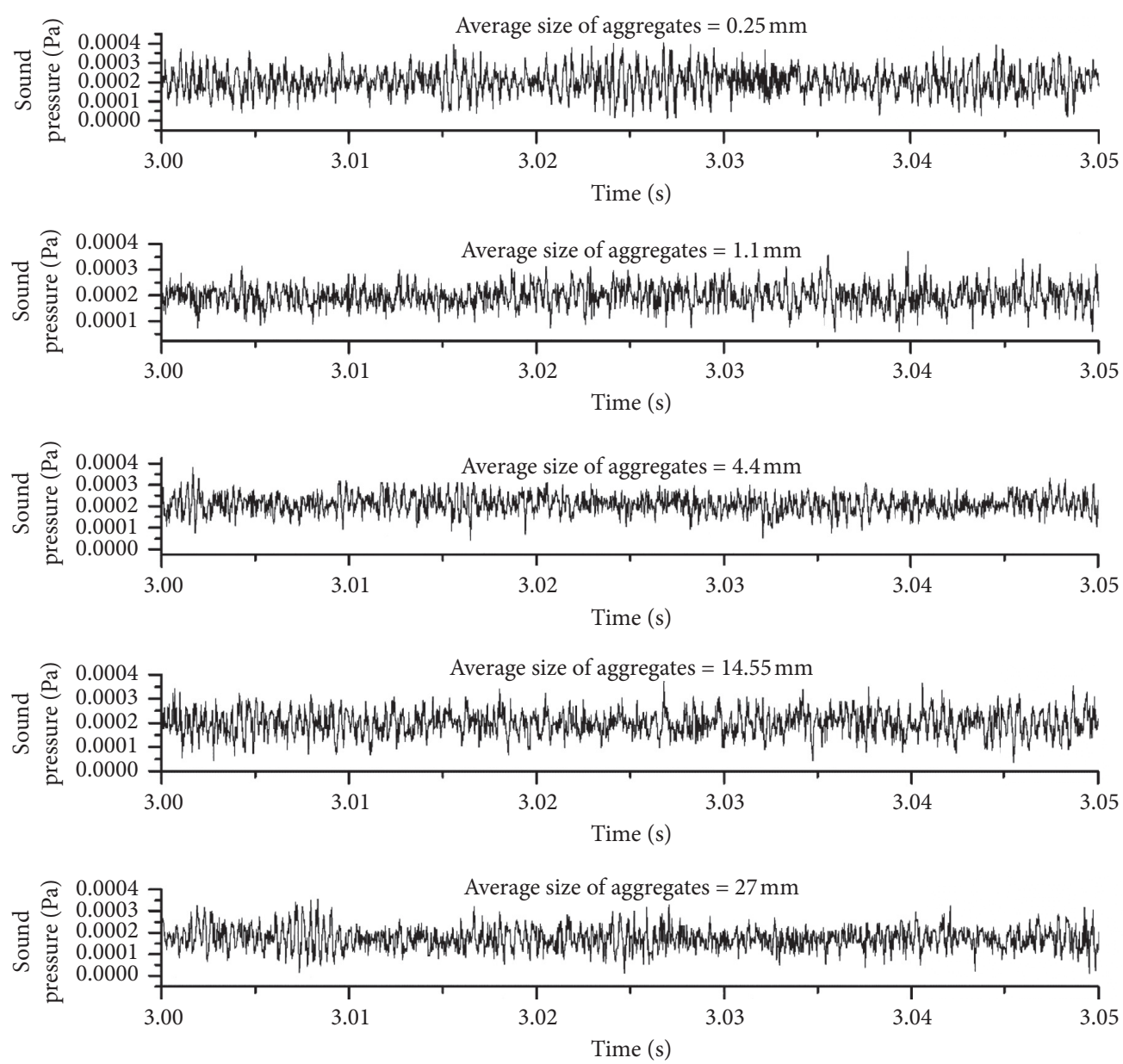

FIgURe 3: Part of the time-domain waveform of the drilling sound signals of five concrete specimens with different-sized aggregates.

TABLE 3: Sound pressure of rocks.

\begin{tabular}{|c|c|c|c|c|}
\hline Feed rate $(\mathrm{mm} / \mathrm{min})$ & 33.1 & 47.4 & 71.6 & 87.7 \\
\hline Average aggregate size $(\mathrm{mm})$ & \multicolumn{4}{|c|}{ Sound pressure $(\mathrm{Pa})$} \\
\hline 0.25 & 0.010492678 & 0.01049946 & 0.010479354 & 0.010518582 \\
\hline 1.1 & 0.010724116 & 0.010664899 & 0.010641966 & 0.010626765 \\
\hline 4.4 & 0.010893667 & 0.010827145 & 0.010836857 & 0.010853092 \\
\hline 14.55 & 0.010868642 & 0.01098472 & 0.010964389 & 0.010964796 \\
\hline 27 & 0.011047972 & 0.011111382 & 0.011047431 & 0.010968967 \\
\hline Average aggregate size $(\mathrm{mm})$ & \multicolumn{4}{|c|}{ Vibration of specimen (g) } \\
\hline 0.25 & 0.017490806 & 0.017121439 & 0.018323736 & 0.017593782 \\
\hline 1.1 & 0.018319802 & 0.017986323 & 0.017900913 & 0.018585228 \\
\hline 4.4 & 0.020071552 & 0.020100486 & 0.019929967 & 0.019774683 \\
\hline 14.55 & 0.020934986 & 0.021593933 & 0.021106782 & 0.021128396 \\
\hline 27 & 0.022671581 & 0.022508665 & 0.022498021 & 0.020596241 \\
\hline Average aggregate size $(\mathrm{mm})$ & \multicolumn{4}{|c|}{ Vibration of drill stem (g) } \\
\hline 0.25 & 0.019289764 & 0.019498957 & 0.019755009 & 0.0202171 \\
\hline 1.1 & 0.020157523 & 0.019809953 & 0.019771174 & 0.019151515 \\
\hline 4.4 & 0.021209608 & 0.020964635 & 0.020814952 & 0.020765467 \\
\hline 14.55 & 0.02224196 & 0.023271593 & 0.023172945 & 0.023574222 \\
\hline 27 & 0.023026962 & 0.023035499 & 0.022533618 & 0.022037818 \\
\hline
\end{tabular}

the sound pressure, and the larger the vibration amplitudes of the specimen and drill stem.

The sound pressure has a higher correlation with the aggregate size than the vibrations do. This is due to the following reasons: the experiments use cylindrical specimens; bench vises are used for clamping; its contact area is rather small; and the clamping conditions cannot be precisely controlled, leading to nonuniform clamping 

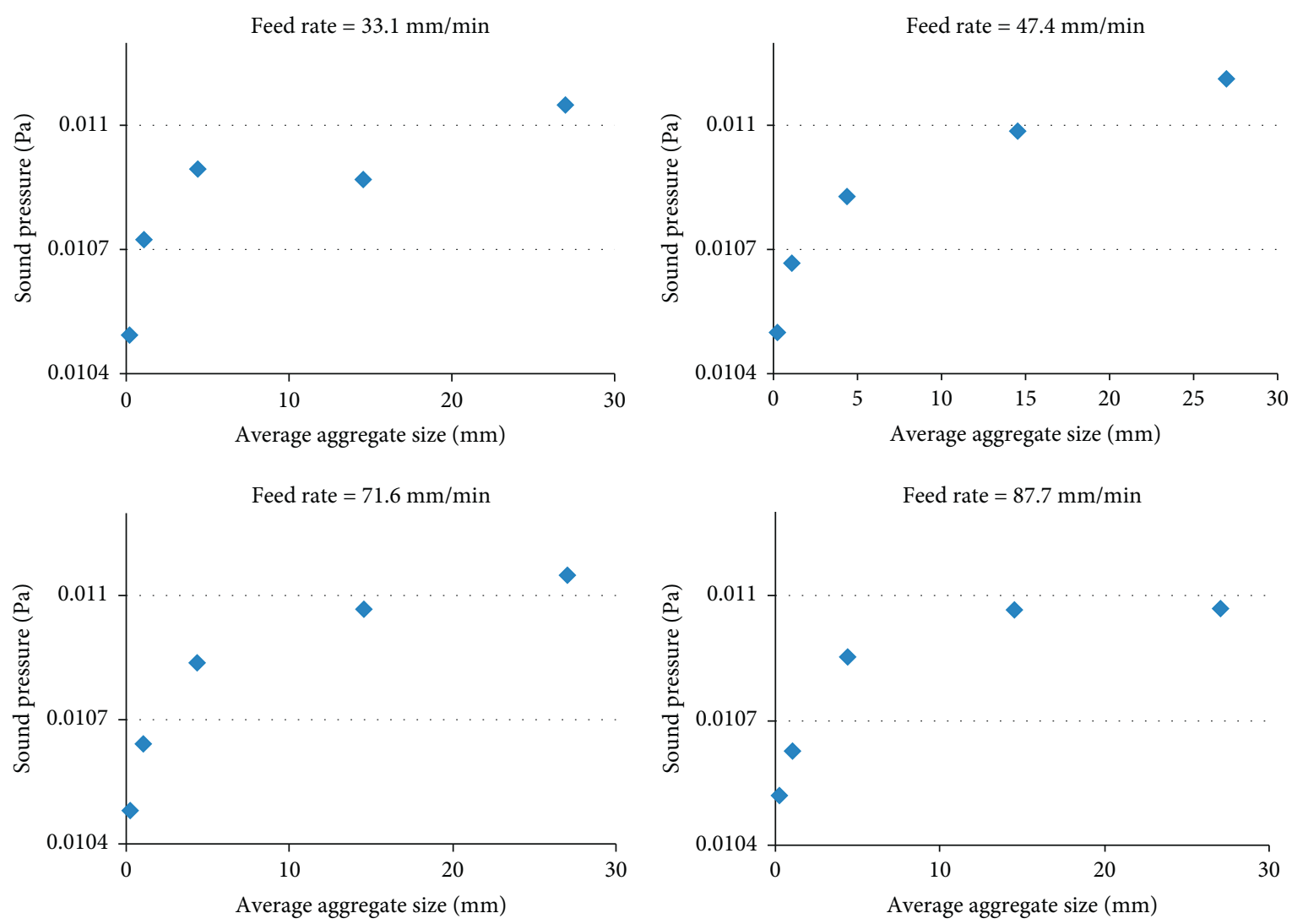

FIGURE 4: Sound pressure vs. average aggregate size.
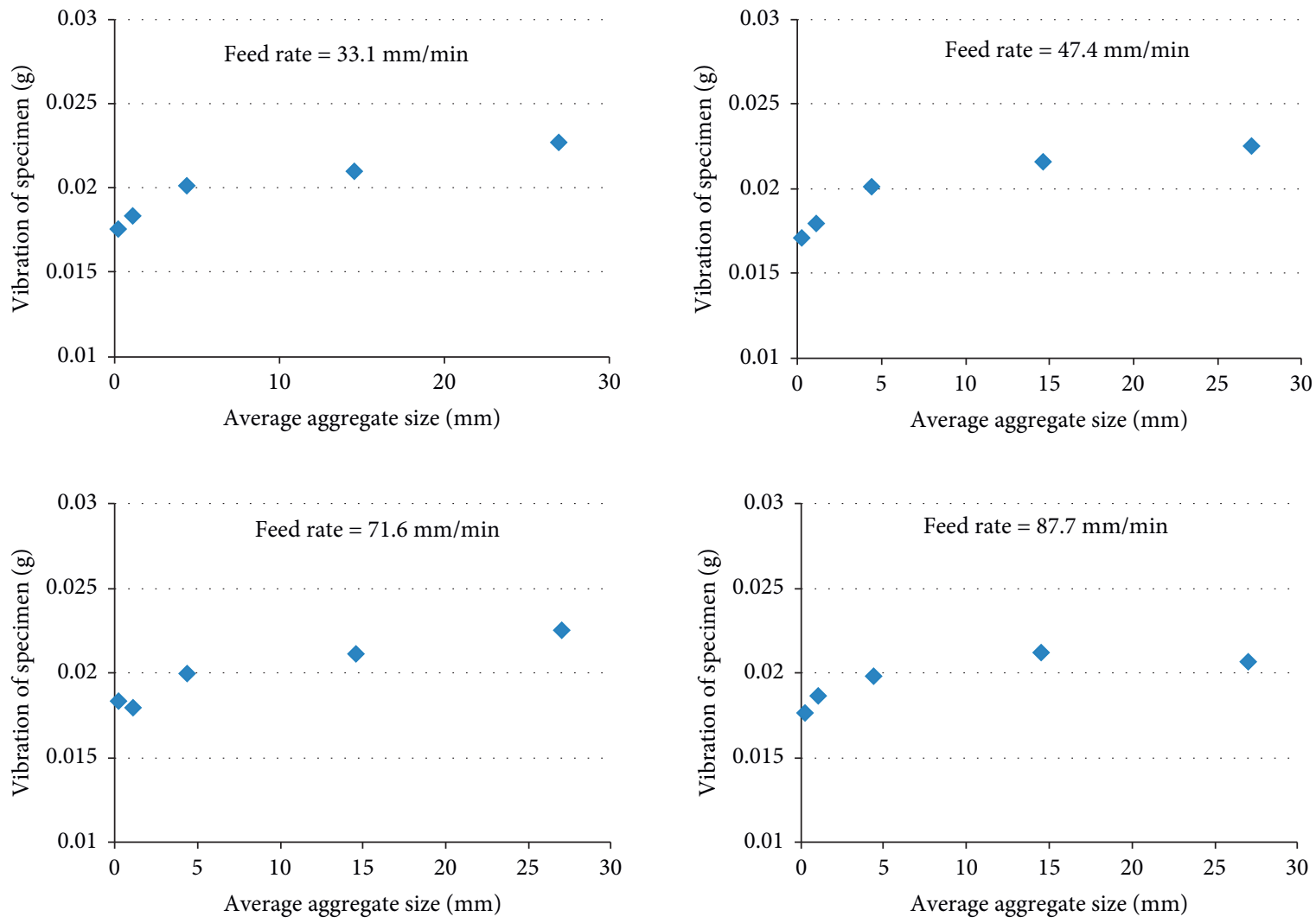

FIGURE 5: Specimen vibration vs. average aggregate size. 

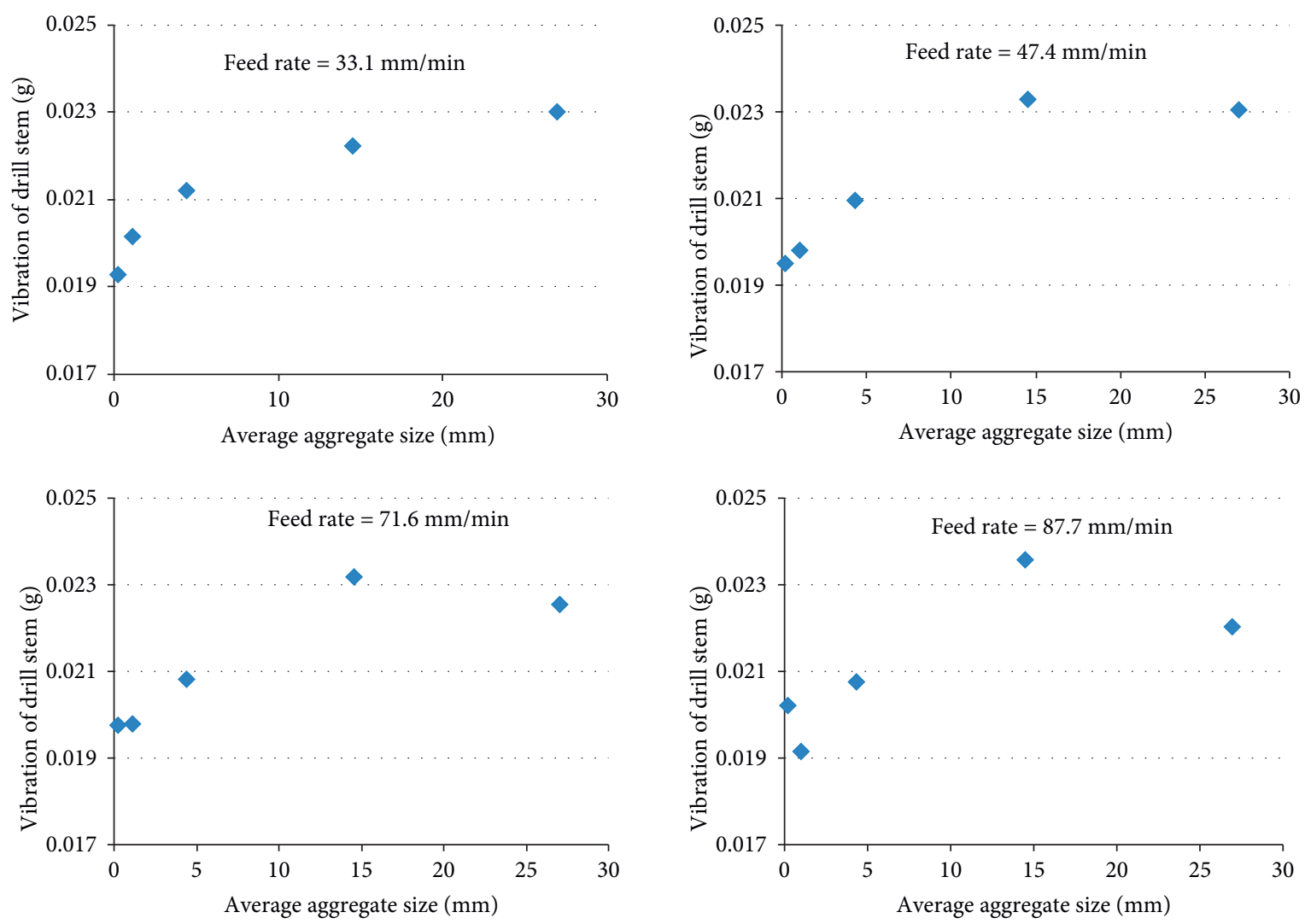

FIGURE 6: Drill stem vibration vs. average aggregate size.

conditions, which will consequently affect the vibration spectra of the specimens and drill stems. However, the effect on the sound spectrum is relatively small. This indicates that, under laboratory conditions, sound can reflect the lithology more accurately.

\section{Frequency-Domain Analysis of the Effect of Concrete Aggregate Sizes on the Drilling Sound and Vibrations}

Figure 7 shows the typical frequency-domain results of sound signals corresponding to the concrete specimens after performing the Fourier transform. Amplitude differences can be observed among the specimens. However, the amplitude characteristic in the frequency domain is similar to that in the time domain and therefore cannot provide more information for lithology identification. The waveform of any frequency spectrum in Figure 7 shows irregular curves like noise, and the energy is distributed in the entire frequency domain; therefore, information characteristics cannot be extracted easily. The primary reasons are that geotechnical materials (even concrete) are usually mixtures of complex compositions and structures, and their vibration spectrum distributions show a greater dispersion. Therefore, it is impossible to consider only a few peak values in the frequency domain as their characteristics.

In the preliminary research, the frequency segmentation method was proposed, which involves segmenting frequency ranges and performing integration to sound pressure or vibration amplitude to obtain the eigenvalues of each frequency. By connecting the eigenvalues, the frequency property model of the specimen can be obtained. This frequency model can be used for lithology identification [28].

The above method was used to process the data of the drilling sound and vibration signals of the specimens of five aggregate sizes. The spectrum property patterns of the drilling sound and vibrations were obtained. Figure 8 shows the typical spectral patterns of the drilling sounds for five specimens with different average aggregate sizes. It can be observed that if the aggregate size varies, the frequency spectrum pattern of the drilling sound will vary as well. The general pattern is that the larger the aggregate size is, the further above the pattern the curve will be. However, its size grade cannot be calculated based only on the form of the curve. The results of the drill stem vibration and specimen vibration are similar to those of the drilling sound.

When observing the pattern curve of each specimen, another trend of the corresponding curve of each aggregate size can be observed: with the increase in the aggregate size, the tilt degree of the curve tends to increase as well. Accordingly, this article proposes an alternative method for clustering. That is, two frequency bands are selected from the high- and low-frequency domains and the ratio of their integral values is calculated. With a trial and error method, it is observed that, to achieve better effects, for low frequency, the frequency band selected is $4000-6000 \mathrm{~Hz}$, and for high frequency, the frequency band selected is $14000-15000 \mathrm{~Hz}$. If 

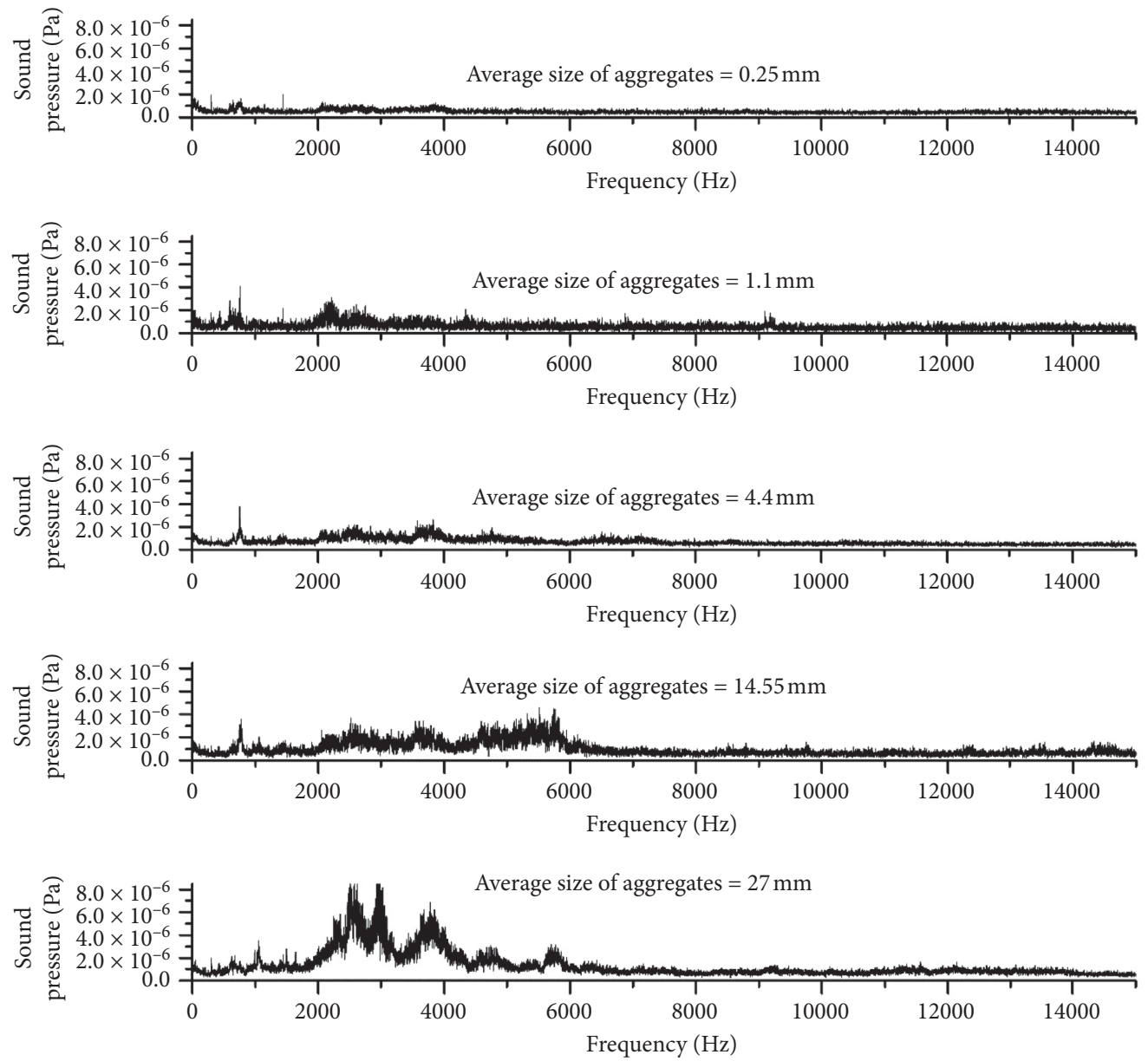

FIgURE 7: Frequency-domain analysis for the drilling sound signals of several specimens.

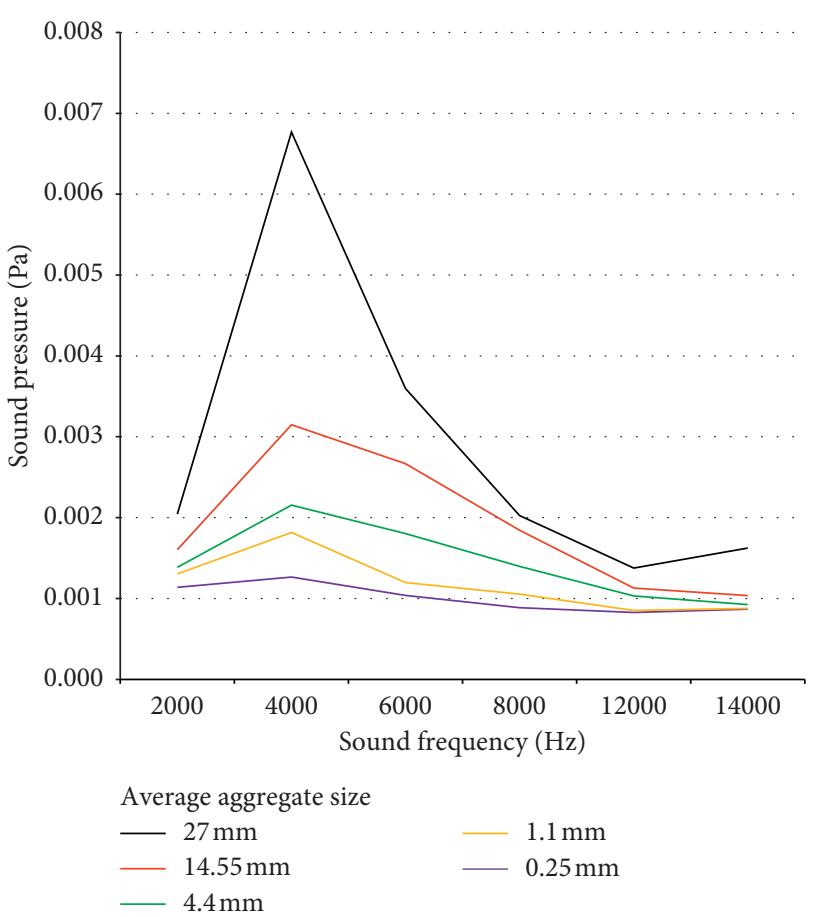

FIGURE 8: Typical spectral patterns of sound pressure while drilling on concrete specimens with different aggregate sizes. the discrete time serial signal is $f(t)$, and $t$ is an integer, then the Fourier transform is the frequency-domain signal

$$
F(\Omega)=F[f(t)] .
$$

The high-low ratio of the frequency is

$$
\lambda=\frac{\sum_{14000}^{1500} F(\Omega)}{\sum_{4000}^{6000} F(\Omega)} .
$$

The eigenvalues obtained by using this method are shown in Table 4, and the corresponding pattern is shown in Figure 9. It can be observed that, with the increase in the aggregate size, the eigenvalues tend to decrease. That is, with the increase in the aggregate size, the integral values of the amplitudes in the low-frequency band increase gradually, but in the high-frequency band, they decrease gradually. This clustering result is significantly better than that obtained with other methods (there is only one exception in Figure 9).

The theoretical basis for this method is as follows: (1) normalization, i.e., the effect incurred by the equipment and the feed rate can be excluded and (2) different aggregate sizes will lead to different frequencies. Therefore, the high-lowfrequency ratio can reflect this difference.

The frequency properties of specimen vibration and drill stem vibration were investigated by using the same method. 
TABle 4: High-low ratio of frequency $(\lambda)$ for concrete samples with different aggregate sizes.

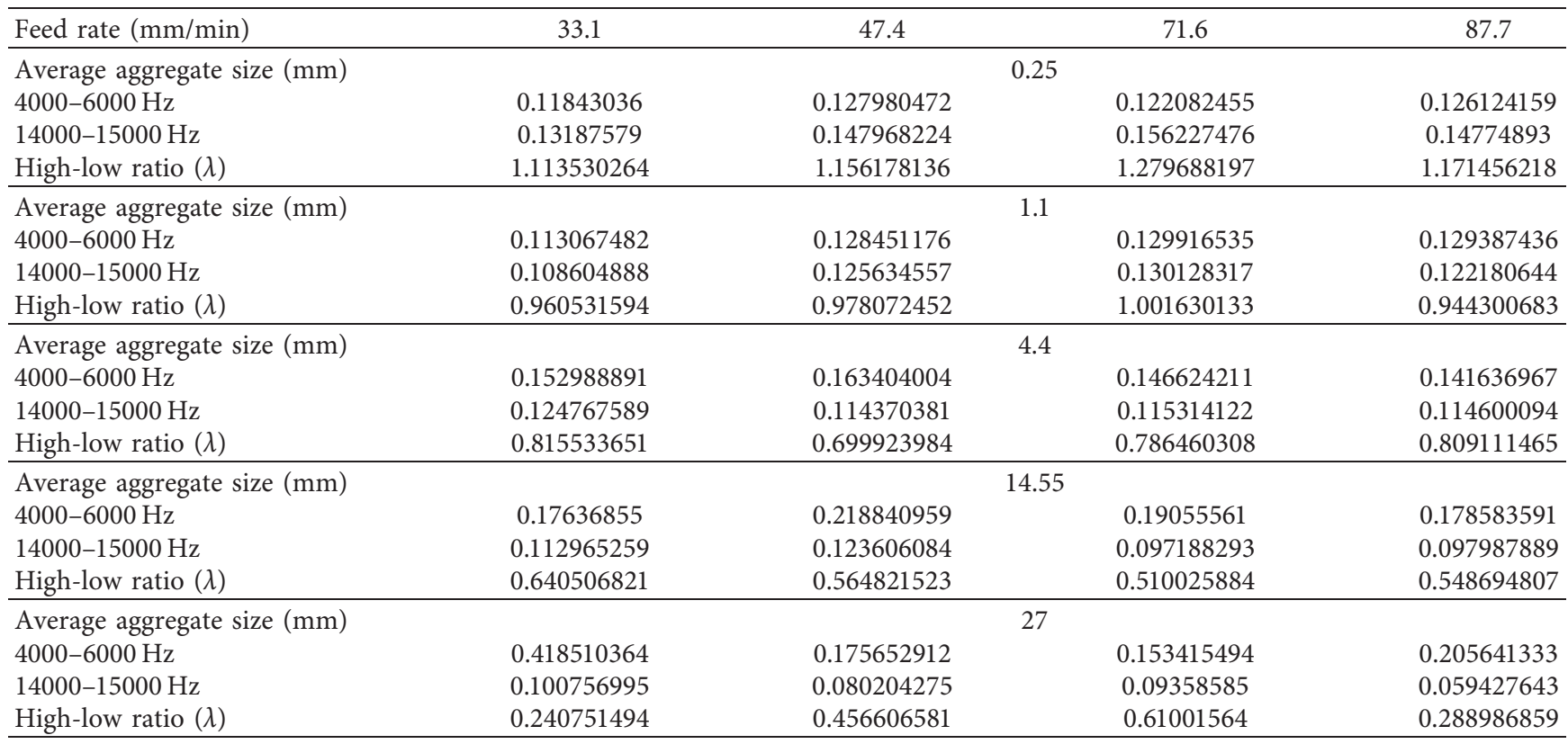

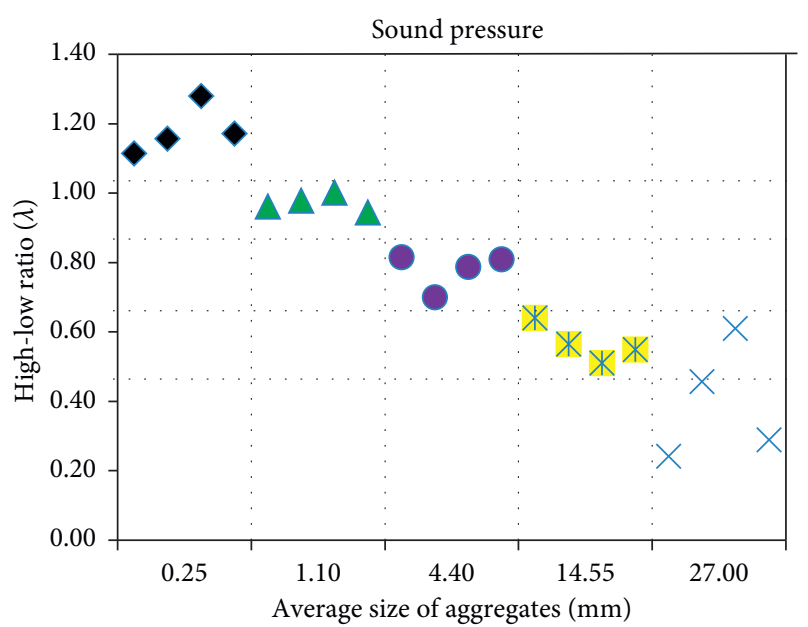

FIGURE 9: High-low ratio of sound frequency vs. aggregate size.

The results are shown in Figures 10 and 11. As shown by the trend lines of the high-low ratio of the frequency and the aggregate sizes, the general tendency is similar to that of sound characteristics. However, in Figure 10, the correlation between the high-low ratio of the specimen frequency and the aggregate size is weaker. It even assumes the reverse tendency in part of the domain, such as Sample 3 (average size: $4.4 \mathrm{~mm}$ ) and Sample 4 (average size: $14.55 \mathrm{~mm}$ ), in which the larger the aggregate size, the smaller the high-low ratio of the frequency of the signals. As shown in Figure 11, which is a scatter plot showing the relationship between the high-low ratio of the drill stem vibration frequency and the aggregate sizes, there are several anomalous points, in particular for Sample 2 (average size: $1.1 \mathrm{~mm}$ ) and Sample 5 (average size: $27 \mathrm{~mm}$ ). The boundary lines are not apparent.

Thus, the high-low ratio $\lambda$ of the frequency is an important index that can reflect concrete aggregate sizes, but it

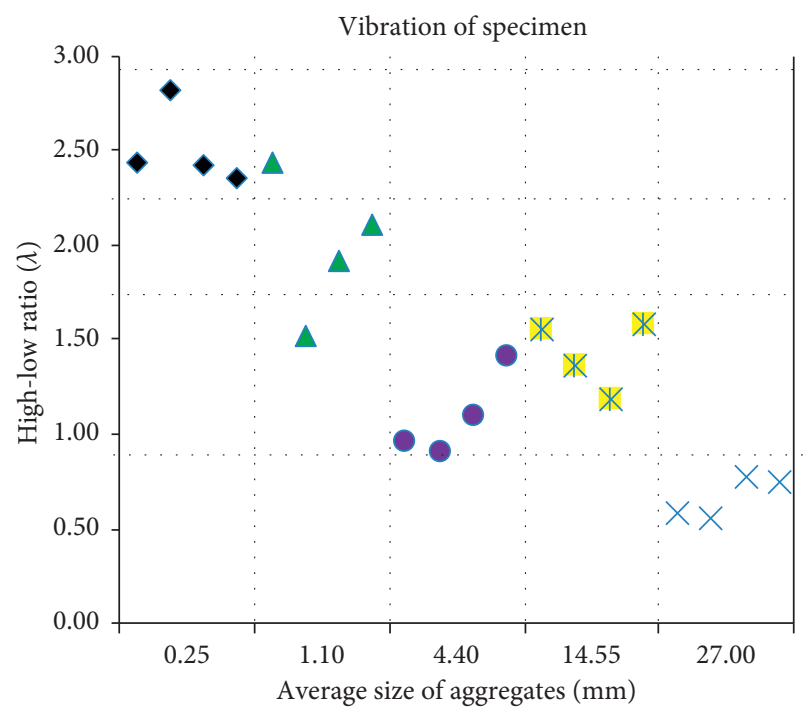

FIgURE 10: High-low ratio of vibration frequency of specimens vs. aggregate size.

is not important enough to reflect concrete aggregate sizes completely. Better solutions need to be devised.

\section{Cluster Approach of Concrete Aggregate Size Based on Drilling Sound and Vibration Spectral Characteristics}

5.1. Amplitude Characteristics Pattern of the Drilling Sound and Vibration Signals. Considering the feed rate in Table 3 as the abscissa and the sound pressure or vibration amplitude as the vertical ordinate, a scatter plot can be drawn. All the scatter points of the same aggregate size were connected to form an amplitude pattern of the drilling sound and vibration signals. This pattern can reflect the concrete 


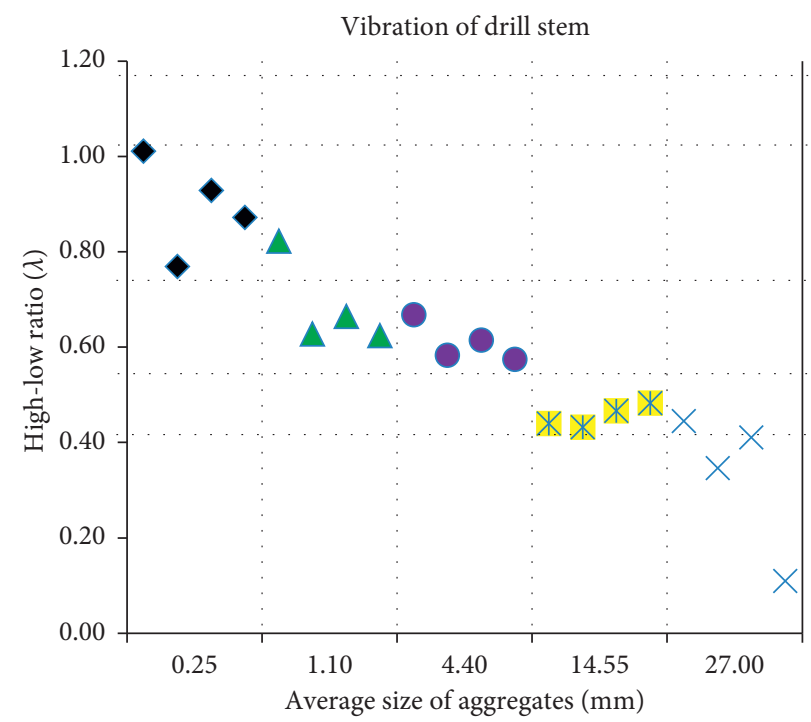

FIGURE 11: High-low ratio of vibration frequency of drill stem vs. aggregate size.

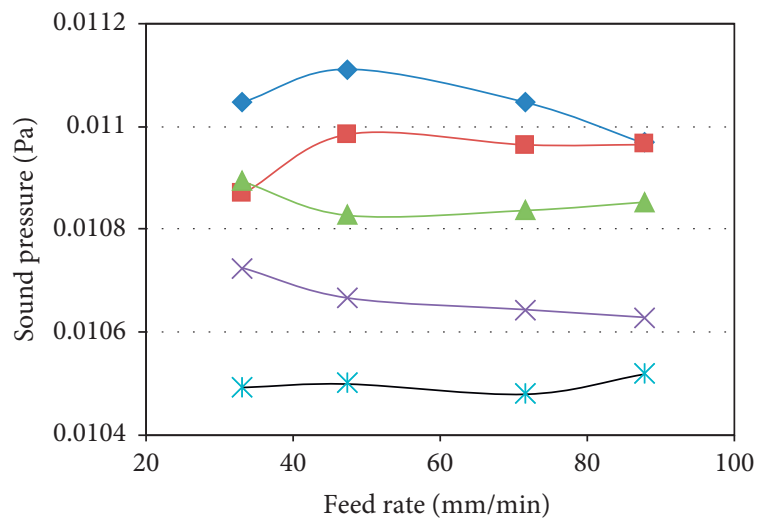

Average aggregate size ( $\mathrm{mm})$

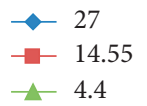

$-4.4$

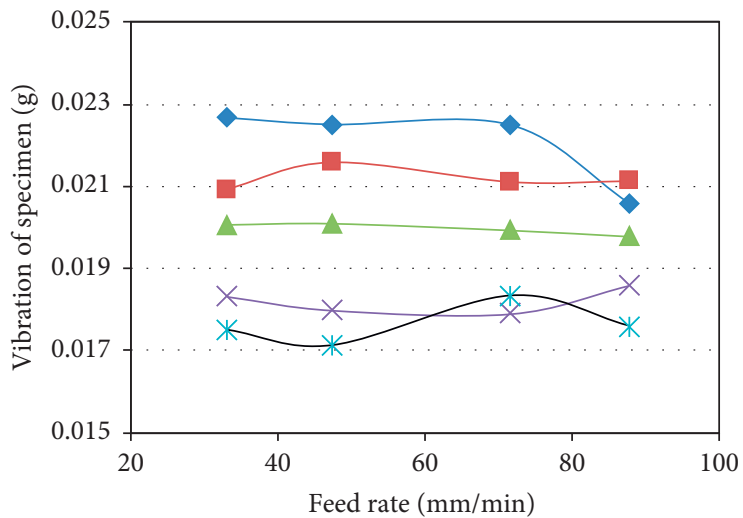

Aggregate size ( $\mathrm{mm})$

$\checkmark 27$

$\times 1.1$

$-14.55$

* 0.25

(a)

(b)

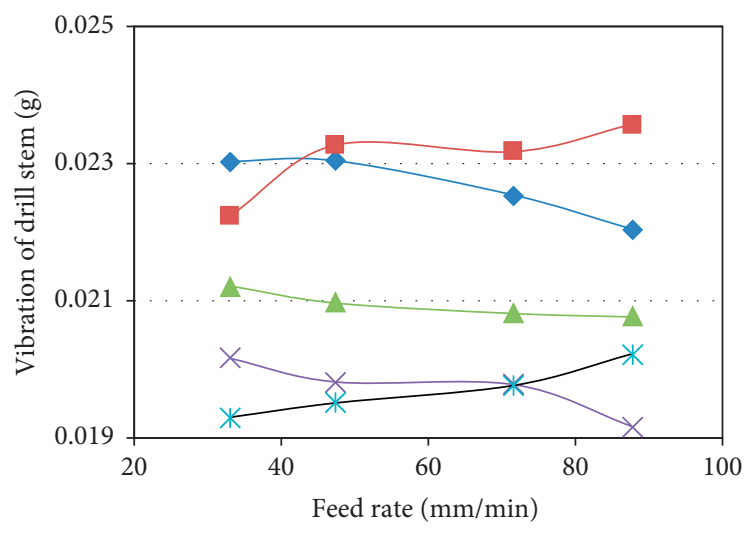

Aggregate size ( $\mathrm{mm})$

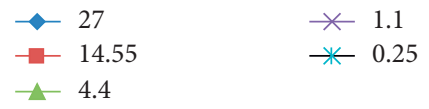

(c)

Figure 12: Aptitude patterns of sound and vibration for different aggregate sizes. 


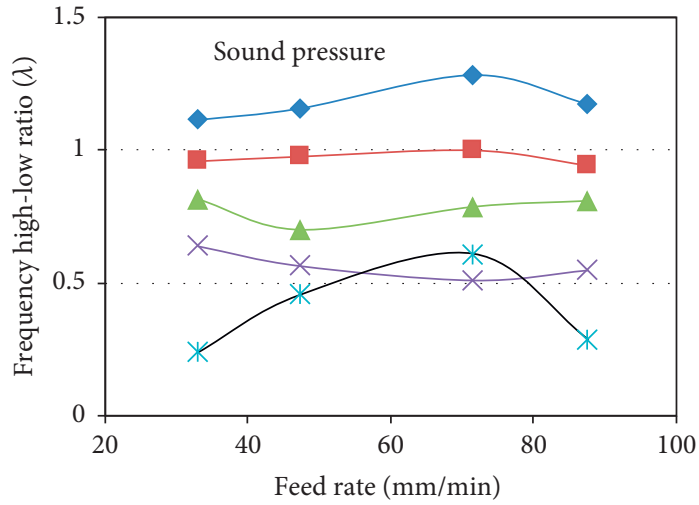

Average aggregate size $(\mathrm{mm})$

$\begin{array}{ll}-0.25 & * 14.55 \\ --1.1 & * 27 \\ -4.4 & \end{array}$

(a)

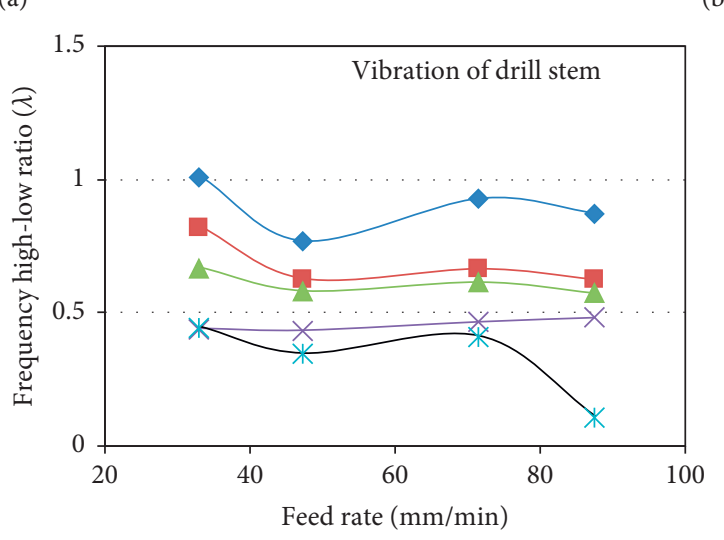

Average aggregate size $(\mathrm{mm})$

$$
\begin{array}{ll}
- & 0.25 \\
- & 1.1 \\
- & 4.4
\end{array}
$$

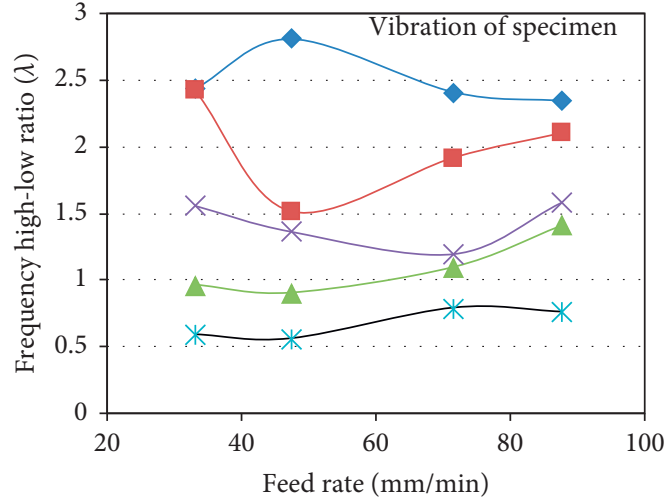

Average aggregate size $(\mathrm{mm})$

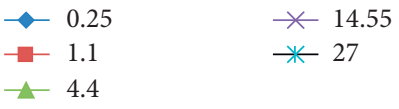

(b)

FiguRE 13: Frequency high-low ratio patterns of sound and vibration for different aggregate sizes.

aggregate sizes more clearly. The improvement is indicated in the comprehensive consideration of the effect of the feed rate and aggregate sizes on the sound vibration spectrum.

As shown in Figure 12(a), the larger the aggregate size is, the greater the sound pressure of the specimens will be, and the further above the pattern the curve will be. Figure 12(b) shows the analysis of the specimen vibration. All the groups show a good clustering effect. Figure 12(c) shows the analysis of the drill stem vibration. Except for Sample 1 (average size: $0.25 \mathrm{~mm}$ ), the clustering results of the other groups are satisfactory in general.

\subsection{Spectral Characteristics Pattern of Drilling Sound Signals.} Considering the feed rate in Table 4 as the abscissa and the sound pressure and vibration frequency property parameter $\lambda$ as the vertical ordinate, a scatter plot can be drawn. All the scatter data points of the same aggregate size are connected to form a pattern graph of the frequency properties of the drilling sound and vibration signals.

As shown in Figure 13, generally, the larger the aggregate size is, the larger the $\lambda$ of the specimen will be, and the further below the pattern the curve will be. This indicates that the larger the aggregate size is, the higher the frequencies will be. Both the "(a) sound pressure pattern" and the "(c) drill stem vibration pattern" conform to this regular pattern. Figure 13(b) shows the analysis of the specimen vibration. The curve positions of Sample 3 (average size: $4.4 \mathrm{~mm}$ ) and Sample 4 (average size: $14.55 \mathrm{~mm}$ ) are inverted, showing that the reliability of this method still needs to be improved.

Generally, drilling holes in rock by a rotary driller can be adopted as a measurement approach of inferring lithology. In this approach, the drilling sound and vibration signals of the feed rates at various grades are recorded, these signals are processed properly, and then the amplitude spectrum 
pattern based on the drilling sound and vibration can be obtained. In this case, a clustering of the rock structure can be achieved.

5.3. Effect of the Feed Rate on the Drilling Sound and Vibrations. Figure 12 shows the effect of the feed rate on the drilling sound pressure and vibrations. From Figure 12(a), it can be observed that, for the five groups of specimen data, with the increase in feed rate, the sound pressure trends remain unchanged. This is also observed in the case of the specimen vibration (Figure 12(b)) and the drill stem vibration (Figure 12(c)). This shows that the amplitude changes in the drilling sound and vibration signals have no significant correlation with the feed rate. Similarly, Figure 13 shows the effect of the feed rate on the high-low ratio $\lambda$ of the drilling sound pressure, the vibration of the concrete specimens, and the vibration of the drill stem. According to the figure, the high-low ratio $\lambda$ has no significant correlation with the feed rate. If drilling is considered as a lithology measurement method, it is not necessary to control the feed rate strictly.

This conclusion is consistent with [28], while it seems to be in conflict with the results reported elsewhere (e.g., $[29-32,34])$. However, the penetration rates in [29-32, 34] were set in the range of $2-6 \mathrm{~mm} / \mathrm{min}$, far smaller than those $(16.5-71.6 \mathrm{~mm} / \mathrm{min})$ in this study. Therefore, the conclusion can be modified considering the following condition: within a certain range, there is no significant correlation between the feed rates and the spectral characteristics of drilling sound and vibrations.

\section{Conclusion and Future Scope}

To infer rock architectural characteristics from sound and vibration signals during diamond core drilling operations, several indoor drilling experiments were conducted by using concrete specimens with different-sized aggregates. The sound and vibration signals were collected and analyzed. The time-domain analysis showed that the amplitude value of the sound pressure and vibration can roughly reflect rock grain sizes. The general trend is that the amplitudes of the sound and vibrations increase with increasing grain sizes. FFT was employed to conduct spectral analysis. The results indicated that the rock grain sizes have a certain effect on the frequency characteristics of sound, specimen vibration, and drill stem vibration while drilling. Based on these results, an index, i.e., high-low ratio of frequencies, was proposed to measure the spectral energy distribution feature. Grain sizes can be estimated by means of the index of high-low ratio.

However, this study was only carried out indoors. It only describes the corresponding relations between different aggregate sizes and vibroacoustic characteristics; hence, causality, namely, mechanism research, between these two is not considered. More theoretical research and field experiments need to be conducted for further advances in the sound and vibration spectral-features-based research and application of rock structure detection.

\section{Data Availability}

The data used to support the findings of this study are available from the corresponding author upon request.

\section{Conflicts of Interest}

The authors declare that there are no conflicts of interest regarding the publication of this paper.

\section{Acknowledgments}

This research was supported by the Zhejiang Provincial Natural Science Foundation of China under Grant no. LY16E040002, the Ningbo Public Welfare Science and Technology Planning Project (No. 2019C50012), the Systematic Project of Guangxi Key Laboratory of Disaster Prevention and Structural Safety (No. 2019ZDK005), Ningbo Natural Science Foundation Project (No. 2019A610394), and the Natural Science Foundation of China Project (No. 51508283). These supporting agencies are gratefully acknowledged. The authors would like to thank Editage (http://www.editage.com) for English language editing.

\section{References}

[1] Z. T. Li, K. I. Itakura, and Y. Z. Ma, "Survey of measurementwhile-drilling technology for small-diameter drilling machines," The Electronic Journal of Geotechnical Engineering, vol. 19, pp. 10267-10282, 2014.

[2] Z. Li and K.-i. Itakura, "An analytical drilling model of drag bits for evaluation of rock strength," Soils and Foundations, vol. 52, no. 2, pp. 216-227, 2012.

[3] Z. T. Li, Y. Z. Ma, L. Yin, F. X. Li, and F. Jin, "Modification of the analytical model for drag bits in rotary rock drilling," in Manufacturing and Engineering Technology (ICMET 2014), A. Sheng and Y. Wang, Eds., pp. 277-281, Taylor \& Francis Group, London, UK, 2014.

[4] D. Servet, S. Nazmi, U. Ibrahim, E. Tamer, A. Deniz, and A. Rasit, "Variation of vertical and horizontal drilling rates depending on some rock properties in the marble quarries," International Journal of Mining Science and Technology, vol. 24, no. 2, pp. 269-273, 2014.

[5] R. Ghosh, "Rock mass characterisation using drill performance monitoring: problems, analysis challenges and limitations," Doctoral Thesis, Lulea University of Technology, Luleå, Sweden, 2015.

[6] H. Tian, "Refinement identification method of digital drilling for tunnel geological," Doctoral Thesis, in Chinese, Shandong University, Jinan, China, 2015.

[7] P. Hatherly, R. Leung, S. Scheding, and D. Robinson, "Drill monitoring results reveal geological conditions in blasthole drilling," International Journal of Rock Mechanics and Mining Sciences, vol. 78, pp. 144-154, 2015.

[8] R. Leung and S. Scheding, "Automated coal seam detection using a modulated specific energy measure in a monitorwhile-drilling context," International Journal of Rock Mechanics and Mining Sciences, vol. 75, pp. 196-209, 2015.

[9] K. M. Babaei and R. Hall, "Processing of measurement while drilling data for rock mass characterization," International Journal of Mining Science and Technology, vol. 26, no. 6, 
pp. 989-994, 2016, https://doi.org/10.1016/j.ijmst.2016.09. 005.

[10] M. D. Khorzoughi, R. Hall, and D. Apel, "Rock fracture density characterization using measurement while drilling (MWD) techniques," International Journal of Mining Science and Technology, vol. 28, no. 6, pp. 859-864, 2018.

[11] N. Al-Shuker, C. Kirby, and M. Brinsdon, "The application of real time downhole drilling dynamic signatures as a possible early indicator of lithology changes," in Proceedings of SPE/ DGS Saudi Arabia Section Technical Symposium and Exhibition, pp. 15-18, Society of Petroleum Engineers, Al-Khobar, Saudi Arabia, May 2011.

[12] A. Esmaeili, B. Elahifar, R. K. Fruhwirth, and G. Thonhauser, "Effect of formations compressive strength on drill string vibrations," in Proceedings of the International Petroleum Technology ConferenceIPTC, Beijing, China, March 2013.

[13] S. Y. Guo, "Recognizing method of coal roadway roof strata based on the vibration characteristics of bolter," Doctoral Thesis, in Chinese, China University of Mining \& Technology, Xuzhou, China, 2019.

[14] W. Li, "Research on theory and method for identification of rock mass properties based on drilling response," Doctoral Thesis, in Chinese, University of Science and Technology Beijing, Beijing, China, 2017.

[15] X. J. Chen, G. L. Chen, G. Song, and X. G. Chen, "Analysis of drilling vibration response based on rock properties," $E x$ ploration Engineering (Rock \&Soil Drilling And Tunneling), vol. 46, no. 10, pp. 20-26, 2019, in Chinese.

[16] Z. D. Jin, C. S. Neng, Z. C. Wang, L. Dong, and Y. Y. Chen, "Vibration signal analysis and application of drill stem based on STFT," Coal Mining Technology, vol. 16, no. 2, pp. 29-32, 2011, in Chinese.

[17] S. Shreedharan, C. Hegde, S. Sharma, and H. Vardhan, "Acoustic fingerprinting for rock identification during drilling," International Journal of Mining and Mineral Engineering, vol. 5, no. 2, pp. 89-105, 2014.

[18] Y. Gao, "Experimental study on drillstring vibro-acoustic logging," Mud Logging Engineering, vol. 10, no. 4, pp. 1-5, 2008, in Chinese.

[19] Y. Gao, "The method of drillstring vibro-acoustic logging and application examples," Mud Logging Engineering, vol. 20, no. 1, pp. 1-7, 2009, in Chinese.

[20] Y. Gao, K. Y. Zou, Y. H. Dong, X. R. Wang, and X. L. Han, "Case studies of drillstring vibro-acoustic logging of ultradeep wells and horizontal wells in Tarim," Mud Logging Engineering, vol. 22, no. 3, pp. 29-36, 2011, in Chinese.

[21] R. W. Liu, B. B. Chen, and C. S. Li, "Research on real-time lithology recognition method," Drilling \& Production Technology, vol. 35, pp. 16-18, 2012, in Chinese.

[22] H. Li, P. Xie, W. F. Yang, D. Q. Xu, and Y. L Xiao, "Vibroacoustic while drilling technique for identifying the weathering crust in northern Tarim Basin," Mud Logging Engineering, vol. 25, no. 3, pp. 10-14, 2014, in Chinese.

[23] I. Lesso, P. Flegner, P. Horovčák, B. Stehlíková, and Z. Sabova, "Some problems in control of the quality of the process of rotary drilling of rocks by using suitable visualization of concurrent vibrations," in Proceedings of the 2014 15th International Carpathian Control Conference (ICCC), IEEE, Velke Karlovice, Czech Republic, May 2014, https://doi.org/ 10.1109/CarpathianCC.2014.6843618.

[24] R. Han, "Approach and application of vibration measure while drilling of drilling rig in coal mines," Doctoral Thesis, in Chinese, China University of Mining and Technology, Xuzhou, China, 2016.
[25] H. Vardhan, G. R. Adhikari, and M. Govinda Raj, "Estimating rock properties using sound levels produced during drilling," International Journal of Rock Mechanics and Mining Sciences, vol. 46, no. 3, pp. 604-612, 2009.

[26] B. Li, "Experimental research on methods of mine seismic while drilling," Master Thesis, in Chinese, China University of Mining and Technology, Xuzhou, China, 2015.

[27] S. W. Liu, M. X. Fu, H. Zhang, and J. Yue, "Vibration mechanism and characteristics analysis of drill rod when drilling roof bolt hole," Journal of China University of Mining \& Technology, vol. 45, no. 5, pp. 893-900, 2016, in Chinese.

[28] Z. T. Li, X. G. Lin, and C. X. Song, "Experimental study on spectral characteristics of sound and vibrations in rock drilling," Chinese Journal of Underground Space and Engineering, vol. 15, no. 4, pp. 1008-1016, 2019, in Chinese.

[29] B. R. Kumar, H. Vardhan, and M. Govindaraj, "Prediction of uniaxial compressive strength, tensile strength and porosity of sedimentary rocks using sound level produced during rotary drilling," Rock Mechanics and Rock Engineering, vol. 44, no. 5, pp. 613-620, 2011, https://doi.org/10.1007/s00603-011-01607.

[30] B. R. Kumar, H. Vardhan, M. Govindaraj, and S. P. Saraswathi, "Artificial neural network model for prediction of rock properties from sound level produced during drilling," Geomechanics and Geoengineering, vol. 8, no. 1, pp. 53-61, 2013.

[31] B. R. Kumar, H. Vardhan, M. Govindaraj, and G. S. Vijay, "Regression analysis and ANN models to predict rock properties from sound levels produced during drilling," International Journal of Rock Mechanics and Mining Sciences, vol. 58, pp. 61-72, 2013, https://doi.org/10.1016/j.ijrmms.2012. 10.002 .

[32] C. V. Kumar, H. Vardhan, C. S. N. Murthy, and N. C. Karmakar, "Estimating rock properties using sound signal dominant frequencies during diamond core drilling operations," Journal of Rock Mechanics and Geotechnical Engineering, vol. 11, no. 4, pp. 850-859, 2019.

[33] C. V. Kumar, H. Vardhan, and C. S. N. Murthy, "Quantification of rock properties using frequency analysis during diamond core drilling operations," Journal of the Institution of Engineers (India): Series D, vol. 100, no. 1, pp. 67-81, 2019.

[34] C. V. Kumar, H. Vardhan, and C. S. N. Murthy, "Multiple regression model for prediction of rock properties using acoustic frequency during core drilling operations," Geomechanics and Geoengineering, vol. 2019, pp. 1-16, 2019.

[35] Masood, "Estimation of sound level produced during drilling of igneous rock samples using a portable drill set-up," Procedia Earth and Planetary Science, vol. 11, pp. 479-492, 2015.

[36] G. Liu, J. L. Zhang, C. Liu, F. Yang, and J. C. Du, "An identification method of vibration signal features when bit drills different mediums," Journal of Vibration and Shock, vol. 36, no. 8, pp. 71-78, 2017, in Chinese.

[37] P. Z. Li, "Study on identification and control methods of the shearer rock drilling," Master Thesis, in Chinese, China University of Mining \& Technology, Beijing, China, 2014.

[38] M. S. Delibalta, S. Kahraman, and R. Comakli, "The usability of noise level from rock cutting for the prediction of physicomechanical properties of rocks," Fluctuation and Noise Letters, vol. 14, no. 1, p. 1550006, 2015.

[39] J. E. Lindqvist, U. Åkesson, and K. Malaga, "Microstructure and functional properties of rock materials," Materials Characterization, vol. 58, no. 11-12, pp. 1183-1188, 2007.

[40] Q. Yu, W. Zhu, P. G. Ranjith, and S. Shao, "Numerical simulation and interpretation of the grain size effect on rock 
strength," Geomechanics and Geophysics for Geo-Energy and Geo-Resources, vol. 4, no. 2, pp. 157-173, 2018.

[41] A. Tuğrul and I. Zarif, "Correlation of mineralogical and textural characteristics with engineering properties of selected granitic rocks from Turkey," Engineering Geology, vol. 51, no. 4, pp. 303-317, 1999.

[42] R. Přikryl, "Some microstructural aspects of strength variation in rocks," International Journal of Rock Mechanics and Mining Sciences, vol. 38, no. 5, pp. 671-682, 2001.

[43] H. Li, H. Li, K. Wang, and C. Liu, "Effect of rock composition microstructure and pore characteristics on its rock mechanics properties," International Journal of Mining Science and Technology, vol. 28, no. 2, pp. 303-308, 2018.

[44] J. W. Cooley and J. W. Tukey, "An algorithm for the machine calculation of complex Fourier series," Mathematics of Computation, vol. 19, no. 90, p. 297, 1965. 